J. Clin. Chem. Clin. Biochem.

Vol. 18, 1980, pp. 1-5

\title{
Isolierung und Nachweis antigenspezifischer T-Zell-Rezeptoren
}

\author{
Von P. Bartmann ${ }^{1}$ ) und W. Brendel \\ Aus dem Institut für Chirurgische Forschung der Ludwig-Maximilians-Universität München
}

(Eingegangen am 12. April/30. Juli 1979)

Zusammenfassung: Durch Injektion von basischem Protein aus Myelin in Meerschweinchen vom Stamm 13 wurde eine experimentelle allergische Encephalomyelitis induziert. Uber an Nylonnetz gekoppeltes Antigen konnten die spezifischen T-Zell-Rezeptoren isoliert werden. Zu ihrem Nachweis wurde ein Phagentest entwickelt. Die Rezeptoren sind nicht mit bekannten Immunglobulinen identisch und besitzen ein Molekulargewicht von 71000.

\section{Isolation and identification of antigen-specific T-cell-receptors}

Summary: Experimental allergic encephalomyelitis was induced by injection of myelin basic protein into guinea pigs strain 13. Specific antigen binding T-cell receptors were isolated by means of a nylon net coupled with antigen. A phage immunoassay was set up as an analytical tool for detection of the receptors. They were found not to be identical with common immunoglobulins and have a molecular weight of 71,000.

\section{Einführung}

Arbeiten von Binz \& Wigzell (1) als auch Krawinkel und Rajewsky $(2,3)$ haben gezeigt, daß T-Lymphocyten einen antigenspezifischen Rezeptor besitzen. Dieser scheint keine Marker der konstanten Region eines Immunglobulins, wohl aber solche des variablen Anteils zu besitzen.

Für die Induktion einer einheitlichen T-Zell-Rezeptorenpopulation bietet sich die experimentelle allergische Encephalomyelitis an. Die experimentelle allergische Encephalomyelitis ist ein Modell für menschliche Demyelinisierungserkränkungen sowie für organspezifische TZell-abhängige Autoimmunerkrankungen. Sie läßt sich in Labortieren durch Injektionen eines aus homologem oder heterolologem Myelin isolierten basischen Proteins mit komplettem Freund'schem Adjuvans induzieren und resultiert in charakteristischen Läsionen im Zentralnervensystem. Teitelbaum et äl. (4) konnte zeigen, daß Meerschweinchen vom Stamm 13 nur mit einer zellulären Immunantwort auf dieses Antigen reagieren.

Wir berichten hier über die İsolierung des für die Er: kennung des basischen Proteins spezifischen T-ZellRezeptors mit Hilfe einer Affinitätsmethode. Żu seinem Nachweis wurde ein Phagentest entwickelt, der u.a. auch zur Bestimmung des freien Antigens dienen kann. Außerdem wurden erste Experimente zur molekularen Charakterisierung des Rezeptors durchgeführt.

\footnotetext{
1) Eingereicht als. Dissertation bei der medizinischen Fakultät der Ludwig-Maximilians-Universität Münchẹn.
}

\section{Material und Methoden}

Ingezüchtete Meerschweinchen Stamm 2 und 13 (400-650 g) waren ein Gescherik des Instituts für Biologisch-Medizinische Forschung, Füllinsdorf, Schweiz.

Alle verwendeten Chemikalien (Reinheitsgrad p.a.) wurden von der Firma Merck (Darmstadt) bezogen.

Antiseren gegen das basische Protein von Kaninchen und Ziege wurden von Dr. D. Teitelbaum, Weizmann-Institut, Rehovot, Israel, zur Verfügung gestellt.

\section{Isolierung des basischen Proteins}

Basisches Protein wurde aus Rückenmark von Rindern nach dem von Hirshfeld et al. (5) angegebenen Verfahren isoliert. Das gereinigte Protein wurde lyophilisiert und bei $-20^{\circ} \mathrm{C}$ aufbewahrt. Seine Homogenität wurde durch Elektrophorese in einem $50 \mathrm{~g} / 1$ Polyacrylamidgel in Gegenwart von $8 \mathrm{~mol} / 1$ Harnstoff und $1 \mathrm{~mol} / 1$ Essigsäure (6) und Anfärben mit Amidoschwarz überprïft. Zur Kontrolle der biologischen Aktivität des basischen Proteins diente der Tierversuch mit klinischer und histologischer Kontrolle.

Kopplung des basischen Proteins an das Nylonnetz

Nylonnetz Nr. 9xxx, Typ 326 mit $90 \mu \mathrm{m}$ Faserdurchmesser wurde von der Schweizer Seidengazefabrik AG, Thal, Schweiz, bezogen. Nach partieller Hydrolyse mit $3 \mathrm{~mol} / 1 \mathrm{HCl}$ bei Raumtemperatur wurde das Nylonnetz mit Bernsteinsäureanhydrid (7), wie von Kiefer (8) beschrieben, umgesetzt. Ein $200 \times 2,5 \mathrm{~cm}$ großer Nylonnetzstreifen wurde dann in einem Erlenmeyerkolben über Nacht mit $200 \mathrm{ml}$ Dimethylformamid, $6 \mathrm{~g} \mathrm{~N}$-Hydroxysuccinimid und $12 \mathrm{~g}$ Dicyclohexylcarbodiimid inkubiert. Danach wurde die Lösung dekantiert und das Nylonnetz je dreimal mit Dimethylformamid, Chloroform und Diethyläther gewaschen. Das getrocknete aktivierte Nylonnetz kann bis zum Gebrauch im Exsikkator über $\mathrm{CaCl}_{2}$ bei $-20^{\circ} \mathrm{C}$ aufbewahrt werden.

Das Nylonnetz wurde in Scheibchen von $25 \mathrm{~mm}$ Durchmesser zerschnitten und diese mit einem zentralen Loch von $2 \mathrm{~mm}$. versehen. 25 Scheibchen wurden dann in $100 \mathrm{ml}$ 0,2 mol/l Borat- 
puffer pH 8,2 mit $100 \mathrm{mg}$ basischem Protein über Nacht bei Raumtemperatur unter konstantem Rühren umgesetzt. Zur quantitativen Analyse der Kopplung wurde mit ${ }^{125}$ Iod markiertes basisches Protein zugesetzt. Von $25,6 \mathrm{KBq}$ eingesetztem ${ }^{125} \mathrm{I}$ markiertem basischen Protein wurden nach sorgfältigem Waschen noch $6,4 \mathrm{KBq}$ als am Nylonnetz gebunden nachgewiesen. Dies entspricht einer Ausbeute von $25 \%$ oder $1 \mathrm{mg}$ basischem Protein pro Scheibchen. Zur Kontrolle wurden Nylonscheibchen verwendet, bei denen der aktivierte Ester vorher bereits gespalten worden war. Die so gemessene unspezifische Bindung des Antigens an das Nylonnetz betrug etwa $0,01 \mathrm{mg}$ basisches Protein pro Scheibchen.

Jeweils 20 mit basischem Protein gekoppelte Nylonscheibchen wurden dann mit $3 \mathrm{~mm}$ starken Teflon-Z wischenringen auf einen Glasstab aufgereiht. Dieser wurde in einer unten mit einem $\mathrm{Ab}$ lauf versehenen $50 \mathrm{ml}$ fassenden Glassäule so plaziert, daß er durch einen Rührmotor mit etwa $5 \mathrm{U} / \mathrm{min}$ gedreht werden konnte.

\section{Rezeptorisolierung}

Meerschweinchen Stamm 13 wurden durch Injektion von $10 \mu \mathrm{g}$ basischem Protein in 0,1 mol/1 NaCl-0,05 mol/1 Natriumphosphat pH 7,3/komplettem Freund'schen Adjuvans 1:2 in jede Fußsohle immunisiert. Die Tiere wurden nach 12 Tagen getötet und die drainierenden Lymphknoten steril entnommen. Diese wurden mit einer Schere zerkleinert, in RPMI 1640 suspendiert und durch ein Netz aus rostfreiem Stahl gedrückt. Die so erhaltene Zellsuspension wurde von Aggregaten befreit und dreimal mit kaltem $\left(+4^{\circ} \mathrm{C}\right)$ Medium gewaschen. Zwischen $2 \times 10^{9}$ und $8 \times 10^{9}$ Zellen in $50 \mathrm{ml}$ RPMI 1640 wurden dann mit dem oben beschriebenen antigengekoppelten Nylonnetz in Anlehnung an das von Kiefer (8) im Detail beschriebene Verfahren für $1 \mathrm{~h} \mathrm{bei}+4^{\circ} \mathrm{C}$ inkubiert. Die durch das basische Protein stimulierten T-Lymphocy ten werden über ihre Rezeptoren an das Antigen (basisches Protein) und damit an das Nylonnetz gebunden, während nicht sensibilisierte Lymphocyten unter diesen Bedingungen nicht an das Nylonnetz gebunden werden.

Diese unspezifischen Zellen können dann durch Elution der Glassäule von den für das basische Protein sensibilisierten Zellen abgetrennt werden. Nach Waschen der Säule mit kaltem Medium wird für $2 \mathrm{~h}$ bei $+25^{\circ} \mathrm{C}$ inkubiert. Die Temperaturerhöhung bewirkt eine Freisetzung der antigenspezifischen Zellen vom Nylonnetz, wobei der antigenerkennende Faktor weiter über das Antigen (basische Protein) an das Netz gebunden bleibt. Die Zellen können dann eluiert und für weitere Experimente gesammelt werden. Thre Anzahl betrug etwa $1 \%$ der insgesamt eingesetzten Zellzahl. Nach dreimaligem Waschen des Nylonnetzes mit phosphatgepufferter physiologischer $\mathrm{NaCl}$-Lösung wird das antigenbindende Material mit 3,5 mol/1 KSCN in phosphatgepufferter physiologischer $\mathrm{NaCl}$-Lösung eluiert und anschließend gegen phosphatgepufferte physiologische $\mathrm{NaCl}$-Lösung dialysiert.

Die Ausbeute an Rezeptorprotein betrug 0,5-1,0 $\mu \mathrm{g}$ pro $10^{10}$ eingesetzte Lymphocyten.

\section{Immunadsorbens}

$1 \mathrm{ml}$ anti-Meerschweinchen Ig-Antiserum vom Kaninchen (Behringwerke, Marburg) wurde mit $0,5 \mathrm{~mol} / 1$ Acetatpuffer $\mathrm{pH} 5$ auf $\mathrm{pH}$ 5,8 eingestellt und tropfenweise $0,3 \mathrm{ml}$ einer $25 \mathrm{~g} / 1$ Glutaraldehydlösung (Sigma, 1:10 verdünnt) zugegeben. Nach zweistündiger Inkubation bei Raumtemperatur wurde das Gel zerkleinert und jeweils dreimal mit $1 \mathrm{~mol} / 1$ Glycin in phosphatgepufferter physiologischer $\mathrm{NaCl}$-Lösung, phosphatgepufferter physiologischer $\mathrm{NaCl}$ Lösung und Rinderserumalbumin gewaschen. Anschließend wurde das Adsorbens so lange mit phosphatgepufferter physiologișcher $\mathrm{NaCl}$-Lösung gewaschen, bis der Überstand eine Absorption von weniger als 0,001 hatte. Die Adsorptionskapazität gegenüber Meerschweinchen-Ig wurde mit anti-basisches Protein-Antiserum von Stamm 2-Meerschweinchen bestimmt.

\section{SDS-Polyacrylamid-Gelelektrophorese}

Die SDS-Polyacrylamid-Gelelektrophorese wurde nach Weber \& Osborn (9) in einer analytischen Disk-Elektrophorese-Apparatur (nach Stegemann, Firma Müller, Hann.-München) durchgeführt. Alle Proteinproben wurden in $10 \mathrm{~g} / 1$ Natriumdodecylsulfat (SDS), $0,05 \mathrm{~mol} / \mathrm{l} \beta$-Mercaptoethanol $10 \mathrm{~min}$ bei Raumtemperatur vor- inkubiert. Die Gele wurden wie unter l.c. (9) angegeben mit Coomassie-Brilliantblau gefärbt und elektrophoretisch (Shandon Entfärbekammer, Chamberley, England) bis auf die Proteinbanden entfärbt. Die Absorption der Banden wurde bei $550 \mathrm{~nm}$ mit dem Zusatzgerät 2410 zum Gilford Spektralphotometer 2400 (Gilford, Oberlin, Ohio) gemessen.

\section{Zellkultur}

Als Kulturmedium diente RPMI 1640, angereichert mit inaktiviertem fötalem Kälberserum (Volumen, $9+1$ ), $100 \mathrm{kE} / 1$ Penicillin, $100 \mathrm{kE} / 1$ Streptomy cin, $1 \%$ MEM-Vitaminlösung ( $\times 100)$, $1 \%$ MEM nicht essentielle Aminosäuren ( $X 100), 25 \mathrm{mmol} / \mathrm{l}$ Hepes-Puffer pH 7,3 sowie $50 \mu \mathrm{mol} / 1 \beta$-Mercaptoethanol. Alle Materialien waren von Gibco, Biocult, Karlsruhe. Die Zellkonzentration betrug 1 bis $5 \times 10^{9} / 1$. Die Kulturen wurden bei $37^{\circ} \mathrm{C}$ und Luft $/ \mathrm{CO}_{2}$ (Volumina, $95+5$ ) im Brutschrank gehalten.

\section{An basisches Protein gekoppelter T4-Phage}

Der Bakteriophage T4 und sein Wirtsbakterium Eschërichia coli B wurden wie von Eder et al. (10) beschrieben gehandhabt. Die Kopplung des basischen Proteins an den Phagen unter Verwendung von Glutaraldehyd als bifunktionellem Reagenz erfolgte in Anlehnung an das von Haimovich et al. (11) beschriebene Verfahren. Basisches Protein wurde in einer Konzentration von $40 \mathrm{~g} / 1$ in $0,05 \mathrm{~mol} / 1$ Natriumphosphat-Puffer pH 6,8 gelöst. Zu $50 \mu \mathrm{l}$ der Lösung des basischen Proteins und $50 \mu \mathrm{l}$ einer Bakteriophagen T4-Suspension ( $10^{13}$ plaque forming units $\left./ \mathrm{ml}\right)$ wurden $20 \mu \mathrm{l}$ Glutaraldehyd $(0,3 \mathrm{ml} / \mathrm{l})$ gegeben. Das Reaktionsgemisch wurde $2 \mathrm{~h}$ bei Raumtemperatur inkubiert und dann durch Zugabe von 0,05 mol/1 Natriumphosphat-Puffer pH 6,8 auf ein Endvolumen von $5 \mathrm{ml}$ gebracht. Präzipitâte wurden durch fünfminütige Zentrifugation mit $7000 \mathrm{~g}$ entfernt. Die Abtrennung des mit basischem Protein gekoppelten Phagen von nicht umgesetztem Antigen erfolgte dann durch Zentrifugation ( $50 \mathrm{~min}$ bei $20000 \mathrm{~g}$ ). Das Zentrifugat wurde mit Phosphatpuffer, dem $20 \mathrm{mg} / 1$ Gelatine zugesetzt waren, gewaschen, mit $1 \mathrm{ml}$ Puffer überschichtet und $12 \mathrm{~h}$ bei $+4^{\circ} \mathrm{C}$ stehengelassen. Danach konnten die Phagen durch leichtes Schütteln resuspendiert werden und das Volumen wurde mit gelatinehaltigem Puffer auf $5 \mathrm{ml}$ aufgefült. Dieser Vorgang der Zentrifugation bei niedriger und hoher Geschwindigkeit, Waschen und langsamer Resuspension wurde zweimal wiederholt. Nach einer letzten Zentrifugation von $5 \mathrm{~min}$ bei $7000 \mathrm{~g}$ erfolgte die Bestimmung der Anzahl der den Kopplungsprozeß überlebenden Phagen durch eine Verdünnungsreihe. Etwa $0,1 \%$ der eingesetzten T4-Bakteriophagen waren nach dem Kopplungsprozeß noch vital. Der modifizierte Phage wurde in gelatinehaltigem Puffer bei $+4{ }^{\circ} \mathrm{C}$ aufbewahrt. Die Inaktivierung des an basisches Protein gekoppelten Phagen durch anti-basisches Protein-Antiserum und antigenbindendes Material von Lymphocyten, sowie die Inhibition dieser Inaktivierung durch freies Antigen wurde wie unter (10) beschrieben durchgeführt.

\section{Ergebnisse und Diskussion}

Um die Spezifität der Inaktivierung von an basisches Protein gekoppeltem T4-Phagen nachzuweisen, wurde die Inaktivierung mit anti-basischem Protein-Antiserum vom Kaninchen untersucht. Abbildung 1 zeigt die dabei erhal tene typische Inaktivierungskurve. Durch Zugabe von $80 \mathrm{ml} / 1$ Polyethylenglykol zum Reaktionsansatz konnte die Empfindlichkeit des Testes noch gesteigert werden (Abb. 1).

Die Bindung des Antikörpers an den an basisches Protein gekoppelten T4-Phagen kann durch freies basisches Protein inhibiert werden, die Lysogenität des Phagen bleibt so erhalten. Man inkubiert dabei zunächst eine konstante Menge Antikörper (ausreichend, um etwa 95\% der Phagen zu inaktivieren) für $1 \mathrm{~h}$ bei $37^{\circ} \mathrm{C}$ mit unterschiedlichen Mengen an basischem Protein, gibt dann den 


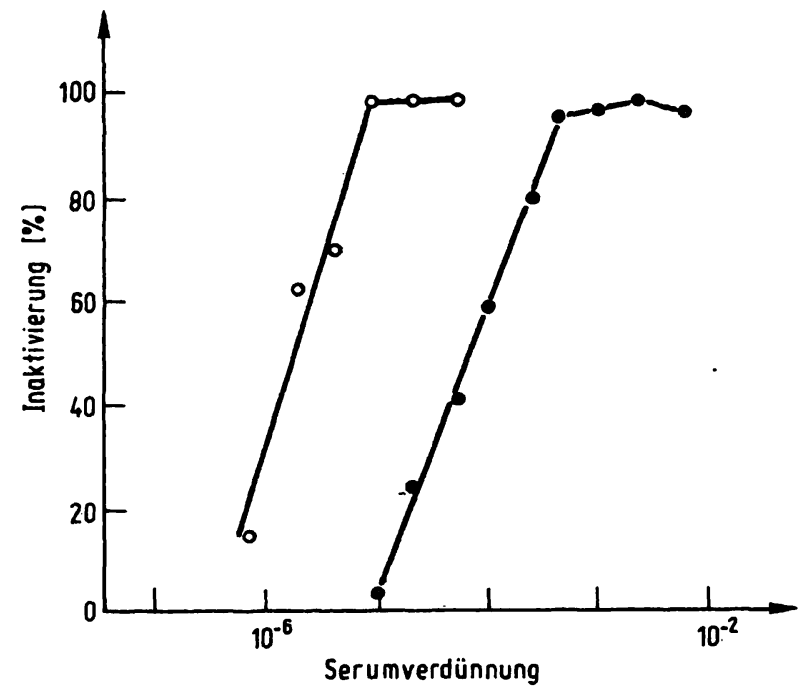

Abb. 1. Inaktivierung von an basisches Protein gekoppeltem T4Phagen mit anti-basisches Protein-Antiserum vom Kaninchen; Komplexinaktivierungsmethode $\mathrm{mit}(\mathrm{O}-\mathrm{O})$ und ohne $(\bullet-)) \mathrm{ml} / 1$ Polyethylenglykol.

Phagen hinzu ( $2 \mathrm{~h}$ bei $\left.37^{\circ} \mathrm{C}\right)$ und bestimmt anschließend die Zahl der lysogenen Phagen (11). Steigende Mengen an zugesetztem Antigen führen so zu einer zunehmenden Blockierung der Antikörper und damit zu einer abnehmenden Inhibition des Phagen.

Das Ergebnis dieses Versuches ist in Abbildung 2 dargestellt. Bei einer Konzentration des basischen Proteins von $0,1 \mathrm{~g} / 1$ ist die Inaktivierung des an basisches Protein gekoppelten T4-Phagen durch das Antiserum komplett inhibiert. Dieses Experiment beweist die Spezifität der Wechselwirkung żwischen anti-basisches Protein-Antiserum und dem an den Phagen gekoppelten Antigen.

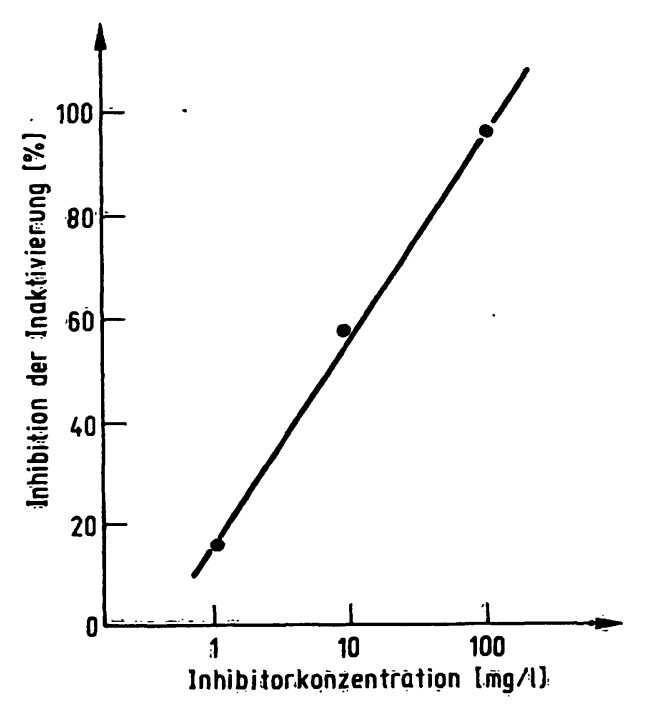

Abb. 2. Inhibition der Inaktivieruing von an basisches Protein gekoppeltem. T4-Phagen durch anti-basisches ProteinAntiserum vom Kaninchen mit freiem basischem Protein als Inhibitor (Komplexinaktivierungsmethodè).
Antigenbindendes Material von T-Lymphocyten wurde wie unter Methoden beschrieben isoliert. Der antigenerkennende Teil dieser Rezeptoren sollte analog dem humoralen Antikörper das an der Oberfläche des Phagen präsentierte basische Protein binden und so zu einer Inaktivierung des Phagen führen. Abbildung 3 zeigt die Inaktivierungskurve, die bei diesem Experiment erhalten wurde. Sie ist der mit dem humoralen Antikörper gemessenen vergleichbar und zeigt, daß die Wechselwirkung zwischen Antigen und Zellrezeptor stark genug ist, um zu einer Inaktivierung des Phagen zu führen.

Zur Erhärtung dieses Befundes wurden die folgenden Kontrollexperimente durchgeführt. Um zu zeigen, daß das von Lymphocyten isolierte Material nicht mit den humoralen Antikörpern identisch ist, wurde es einer wiederholten Immunadsorption mit vernetztem anti-Meerschwinchen-Immunglobulin-Antiserum unterworfen. Dabei ergab sich keine Differenz in der Inaktivierungskapazität des modifizierten Phagen vor und nach der Adsorption. Dieses Ergebnis zeigt, daß das Rezeptormaterial nicht mit einem Immunglobulin identisch ist.

Um sicherzustellen, daß unter den gewählten Bedingungen keine meßbaren Mengen an humoralen Antikörpern gegen das basische Protein gebildet werden, wurde das Serum der immunisierten Tiere sowohl mit dem Präzipitationstest als auch dem Phagentest analysiert. Bei beiden Untersuchungen konnten keine Antikörper im Serum der mit basischem Proteın immunisierten Meerschweinchen vom Stamm 13 nachgewiesen werden.

Zum Ausschluß von unspezifischem, gleichwohl den an basisches Protein gekoppelten T4-Phagen inaktivierenden Material, wurden 10 Meerschweinchen Stamm 13 mit $10 \mu \mathrm{g}$ Ovalbumin in komplettem Freund'schen

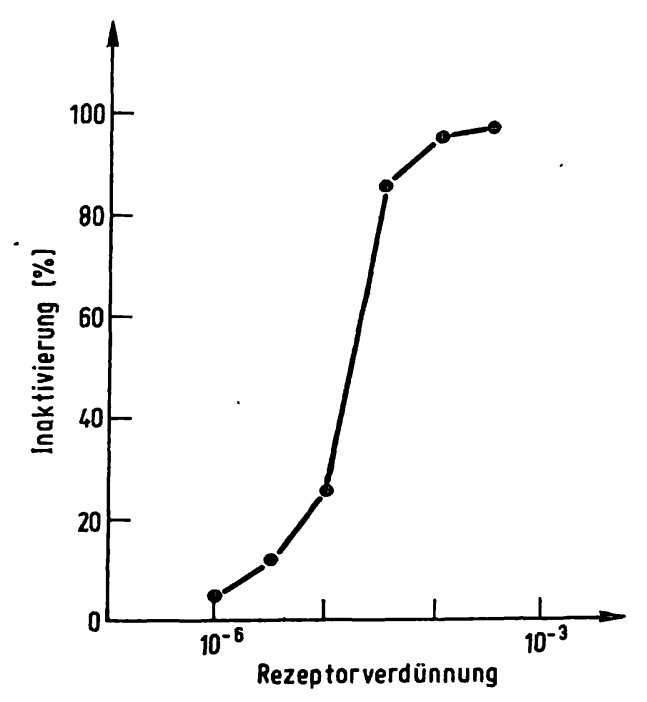

$\mathrm{Abb}$. 3. Inaktivierung von an basisches Protein gekoppeltem T4Phagen mit Rezeptormaterial von T-Lymphocyten aus mit basischem Protein immunisierten Meerschweinchen Stamm 13. Die Konzentration an Rezeptorprotein in der Ausgangslösung betrug $2 \mathrm{mg} / \mathrm{l}$. 
Adjuvans durch Injektion in alle vier Fußsohlen immunisiert. Die weitere Versuchsdurchführung erfolgte analog den für die Immunisierung mit basischem Protein beschriebenen Bedingungen. Wie Abbildung 4 a zeigt, konnte dann über einen weiten Konzentrationsbereich keine Inaktivierung von an basisches Protein gekoppeltem T4-Phagen mit diesem Material nachgewiesen werden. Das gleiche Resultat wurde bei Verwendung von Lymphocyten aus nicht sensibilisierten Meerschweinchen erhalten. Diese Experimente zeigen, daß unspezifische Reaktionen für die beobachtete Inaktivierung des Phagen offensichtlich keine Rolle spielen.

Um zu zeigen, daß der antigenspezifische Rezeptor von den an das Nylonnetz gebundenen Zellen gebildet wird, wurden diese spezifischen Zellen nach Elution von der Affinitätssäule für zwei Tage in Zellkultur gehalten. Die Vitalität der Zellen wurde mit Trypanblau überprüft. Nach dieser Inkubationszeit wurden die Zellen wie beschrieben den einzelnen Schritten der Rezeptorisolierung unterworfen. Abbildung $4 \mathrm{~b}$ zeigt, daß in der Tat wieder phageninaktivierendes Material von den Zellen gebildet worden war.

Zur morphologischen Analyse der spezifischen Zellen wurden diese nach May-Grünwald-Färbung lichtmikroskopisch untersucht. Es handelte sich um eine homogene

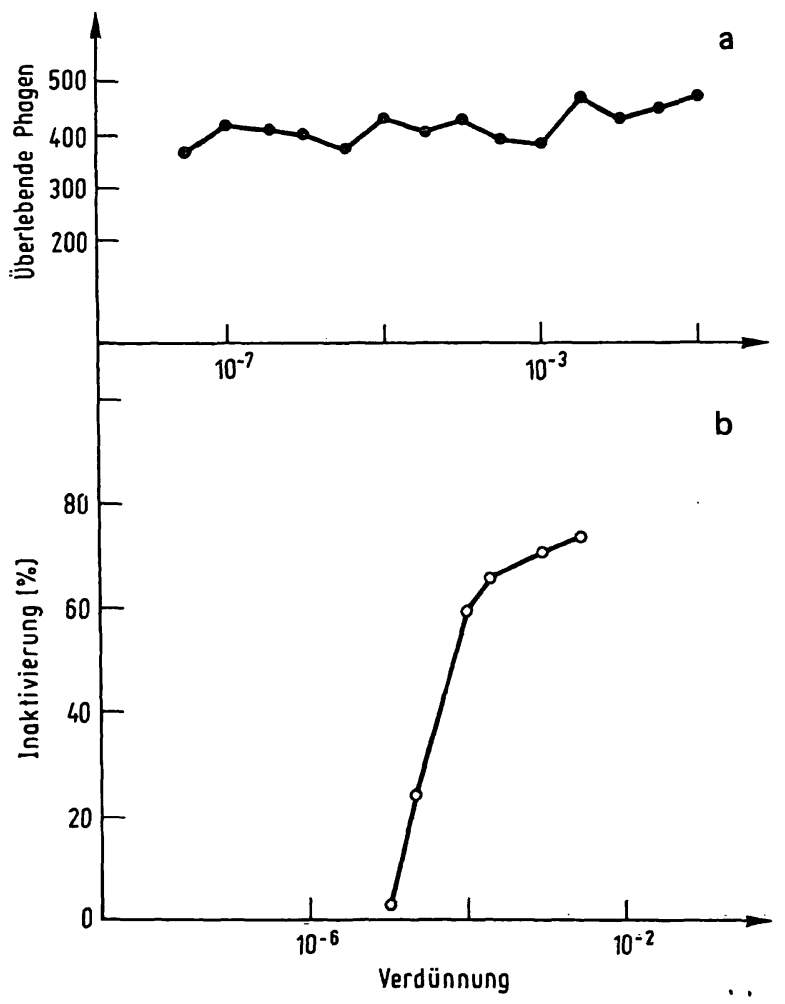

Abb. 4a.'Inaktivierung von an basisches Protein gekoppeltem T4Phagen mit Material von Meerschweinchen Stamm 13, die mit $10 \mu \mathrm{g}$ Eialbumin und komplettem Freund'schen Adjuvans immunisiert wurden.

Abb. 4 b. Inaktivierung von an basisches Protein gekoppeltem T4Phagen mit Material von gegen basisches Protein sensitiven T-Lymphocyten nach zweitägiger Zellkultur bei vorheriger Passage über die Affinitätssäule. Die Konzentration an Rezeptorprotein in der Ausgangslösung betrug $0,5 \mathrm{mg} / \mathrm{l}$.
Zellpopulation mit mehr als 99\% Lymphocyten. Zum Ausschluß von B-Lymphocyten wurden die Zellen mit Fluorescein-gekoppeltem anti-Meerschweinchen-Ig vom Kaninchen (Behringwerke, Marburg) inkubiert und fluoreszenzmikroskopisch untersucht. Weniger als $2 \%$ der Zellen zeigten eine Fluoreszenz und sind deshalb der Reihe der B-Lymphocyten zuzuordnen. Mit einem antiMeerschweinchen-Thymocyten-Antiserum vom Kaninchen (Geschenk von D. Teitelbaum, Weiżmạnn Institut, Rehovot, Israel) wurde schließlich noch eị Cytotoxizitätstest durchgeführt. Der dabei gemessene cy totoxische Index von 92,0 unterstreicht die obigen Ergebnisse. Bei der Fraktion der anitigen-speżifischen Zellen handelt es sich um eine fast reine T-Lymphocy tenpopulation. Mit den bekannten Methoden läßt sich jedoch die Anwesenheit anderer Zelltypen nicht ganz ausschließen.

Unterschiedliche Ergebnisse liegen über das Molekulargewicht des antigenspezifischen T-Zell-Rezeptors vor (1-3). Deshalb wurde das Rezeptormaterial von 10 Meerschweinchen nach Testung mit dem Phagentest einer SDS-Polyacrylamid-Gelelektrophorese in Gegenwart von $0,05 \mathrm{~mol} / 1 \beta$-Mercaptoethanol unterworfen. Abbildung 5

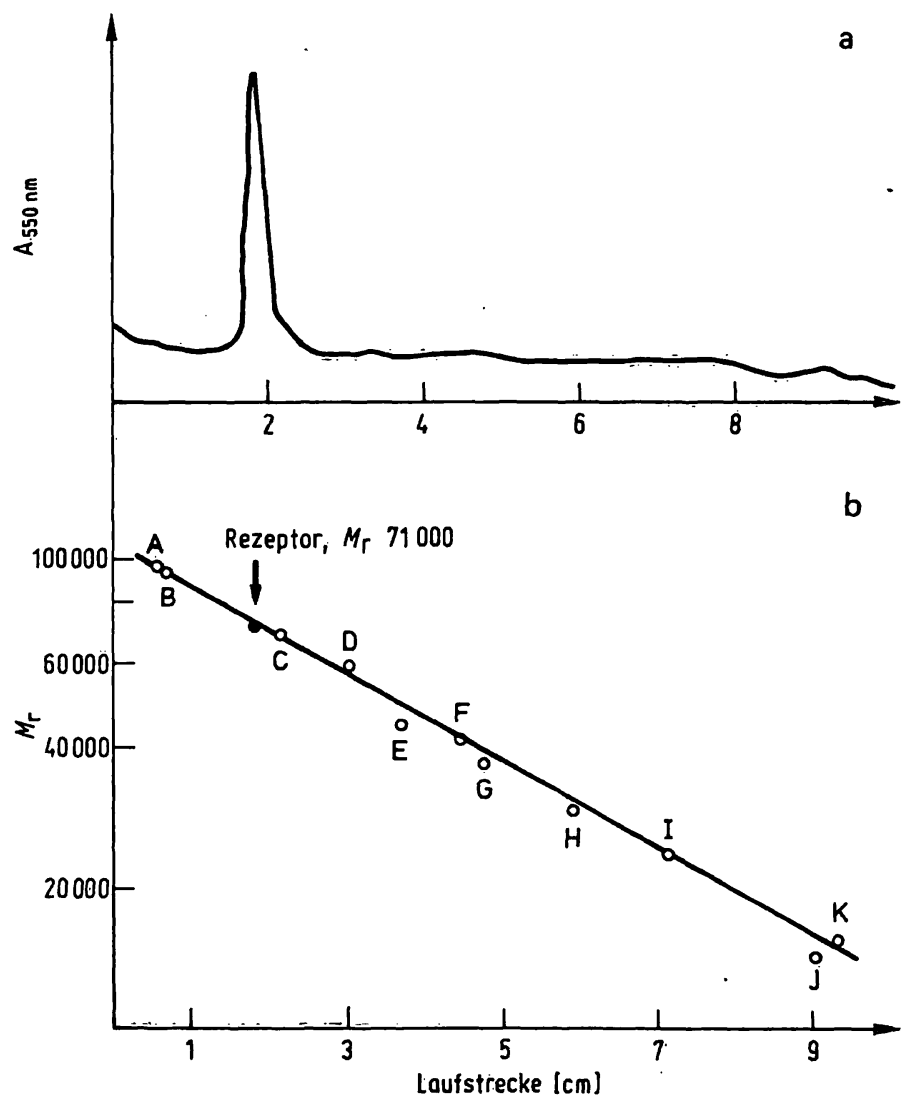

Abb. 5 a. SDS-Polyacrylamid-Gelelektrophorese von Rezeptormaterial gegen basisches Protein sensibilisierter T-Lymphocyten vón Meerschweinchèn Stamm 13; Gelscan nach Anfậrben der Proteinbande mit Coomassieblau.

Abb. 5 b. Standardgerade zur Molekulargewichtsbestîmmung; A Phosphorylase b; B $L$-Phenylalanin: tRNA Ligase, $\beta$-Untereinheit; $C$ Rinderserumalbumin; D Pyruvatkinase, $E$ Tryptophan-Synthase, $\beta$-Untereinheit; $F$ $L$-Phẹnylalanin: $t R N A$ Ligase, $\alpha$-Untereinheit; $G$ Glycerinaldehyd-3-phosphat-dehydrogenase; $\dot{H}$ Tryptophan-Synthase, $\alpha$-Untereinheit; I Trypsin; J. Ribonuclease; K Lysozym. 
zeigt den Gelscan nach Elektrophorese und Anfärben mit Coomassie-Brilliantblau. Nur eine einzige Bande ist sichtbar bei einer eingesetzten Proteinmenge von etwa $2 \mu \mathrm{g}$. Eine Koelektrophorese des Rezeptormaterials mit Rinderserumalbumin ergab eine Trennung in zwei Banden, wobei die schneller wandernde Bande dem Rinderserumalbumin entsprach. Zur Molekulargewichtsbestimmung wurde mit Hilfe von 11 Proteinen eine Standardgerade aufgestellt. Daraus ließ sich das Molekulargewicht des Rezeptormaterials zu 71000 bestimmen (Abb. 5b).

Wie die obigen Experimente zeigen, präsentieren T-Lymphocyten an ihrer Oberfläche einen antigenspezifischen Rezeptor. Durch eine Affinitätsmethode konnte dieser Rezeptor angereichert werden. Er ist offensichtlich nicht mit bisher bekannten Immunglobulinen identisch. Sein Molekulargewicht von 71000 unter denaturierenden $\mathrm{Be}$ dingungen schließt ein polymeres Vorliegen in vivo (wie z.B. für IgG und IgM bekannt) nicht aus. Mit Hilfe eines Phagentestes war es möglich, dieses antigenspezifische Protein nachzuweisen. Diese analytische Methode ist prinzipiell auch in anderen Systemen anwendbar. Der an basisches Protein gekoppelte T4-Phage kann jetzt mit Hilfe des Inhibitionsverfahrens durch freies Antigen auch zur Analyse von Liquorproben verwendet werden, um die Anwesenheit des basischen Proteins bei demyelini- sierenden Erkrankungen des Zentralnervensystems nachzuweisen. Da der modifizierte Phage wochenlang bei $+4{ }^{\circ} \mathrm{C}$ stabil bleibt, bietet sich hier eine analy tische Methode für die Routine an.

Die Isolierung eines antigenspezifischen T-Zell-Rezeptors sollte auch einen neuen klinisch-therapeutischen Ansatz ermöglichen (1). Durch Immunisierung von Versuchstieren mit diesem Rezeptor könnte ein Antiserum gewonnen werden, welches die spezifisch sensibilisierten Lymphocyten blockieren oder in Gegenwart von Konplement lysieren würde. Diese Arbeit ist so der erste Schritt zu einer spezifischen immunsuppressiven Therapie der experimentellen allergischen Encephalomyelitis (oder anderer T-Zell-abhängiger Immunerkrankungen).

\section{Danksagung}

Wir sind den Herren Dr.J. Eder und Dr. B. U. v. Specht für ihre Unterstützung und viele nützliche Hinweise dankbar. Frau $M$. Waltenberger leistete ausgezeichnete technische Assistenz. Diese Arbeit wurde aus Mitteln des SFB 37 der Deutschen Forschungsgemeinschaft unterstützt. Wir danken dem Institut für Biologisch-Medizinische Forschung, Füllinsdorf, Schweiz, für Meerschweinchen der Stämme 2 und 13.

\section{Literatur}

1. Janeway, C. A., Jr., Wigzell, H. \& Binz, H. (1976), Scand. J. Immunol. 5, 993-1001.

2. Krawinkel, U. \& Rajewsky, K. (1976), Eur. J. Immunol. 6, 529-536.

3. Krawinkel, U., Cramer, M., Imanishi-Kari, T., Jack, R. S. Rajewsky, K. \& Mäkelä, O. (1977), Eur. J. İmmunọl. 8, $566-573$

4. Teitelbaum, D., Webb, C., Arnon, R. \& Sela, M. (1977), Cellular Immunology 26, 265-271.

5. Hirshfeld, H., Teitelbaum, D., Amon, R. \& Sela, M. (1970), FEBS Letters 7, 317-320.

6. Deibler, G. E., Martenson, R. E. \& Kies, M. W. (1972), Prep. Biochem. 2, 139-165.

7. Edelman, G. M., Rutishauser, U. \& Millette, C. F. (1971), Proc. Nat. Acad. Sci. USA 68, 2153.

8. Kiefer, H. (1973), Eur. J. Immunol. 3, 181-183.

9. Weber, K. \& Osborn, M. (1969), J. Biol. Chem. 244, 44064412.

10. Eder, J., Osanai, M., Mane, S. \& Rembold, H. (1977), Biochim. Biophys. Acta 496, 401-411.

11. Haimovich, J., Hurwitz, E., Novik, N. \& Sela, M. (1970), Biochim. Biophys. Acta 207, 115-124.

Dr. rer. nat. Peter Bartmann Institut für Chirurgische Forschung Klinikum Großhadern

Postfach 701260

D-8000 München 70 
"

. 。 